Wilfrid Laurier University

Scholars Commons @ Laurier

Biology Faculty Publications

Biology

2002

\title{
Impact of Flower Harvesting on the Salt Marsh Plant Limonium carolinianum
}

Jennifer L. Baltzer

Wilfrid Laurier University, jbaltzer@wlu.ca

Edward G. Reekie

Acadia University

Heather L. Hewlin

Acadia University

Philip D. Taylor

Acadia University

J. Sherman Boates

Nova Scotia Department of Natural Resources

Follow this and additional works at: https://scholars.wlu.ca/biol_faculty

\section{Recommended Citation}

Baltzer, Jennifer L.; Reekie, Edward G.; Hewlin, Heather L.; Taylor, Philip D.; and Boates, J. Sherman, "Impact of Flower Harvesting on the Salt Marsh Plant Limonium carolinianum" (2002). Biology Faculty Publications. 8.

https://scholars.wlu.ca/biol_faculty/8

This Article is brought to you for free and open access by the Biology at Scholars Commons @ Laurier. It has been accepted for inclusion in Biology Faculty Publications by an authorized administrator of Scholars Commons @ Laurier. For more information, please contact scholarscommons@wlu.ca. 


\title{
Impact of flower harvesting on the salt marsh plant Limonium carolinianum
}

\author{
Jennifer L. Baltzer, Edward G. Reekie, Heather L. Hewlin, Philip D. Taylor, and \\ J. Sherman Boates
}

\begin{abstract}
Because of the potentially detrimental effects of seed production on adult survivorship and growth, moderate flower harvesting may have little negative impact on population growth of long-lived perennial plants such as Limonium carolinianum (Walter) Britton. We examined this by collecting data on survivorship, growth, and fecundity of an unharvested population over a period of 5 years and conducted a controlled experiment to examine the effect of harvesting on adult survivorship and growth over a 3-year period. Data were summarized in the form of a stagestructured matrix population model with a stochastic element that incorporated year-to-year variation in transition probabilities. Contrary to our original hypothesis, we found that preventing seed set through removal of flowers did not increase adult survivorship or growth. By determining the harvest level that reduced population growth rate to 1.0 , we estimated the maximum sustainable harvest level to be $16 \%$, a value that is approximately half that of reported harvest levels on accessible marshes in the study area. In spite of this, the reported harvest levels are unlikely to drive local populations to extinction in the foreseeable future. Providing the adult population size is $>100$ and harvest levels are $<90 \%$, time to local extinction will exceed 100 years. This is a function of the very high survivorship of adults in this species and the fact that harvesting has no negative impact on adult survivorship or growth. However, because of the long preadult phase in this species (8-9 years) and the fact that fecundity of young adults is low, recovery from overharvesting is extremely slow. Adult population size can be reduced to $25 \%$ of its original value in 7 years at high harvest levels, but it will take 34 years on average to recover once harvesting is terminated.
\end{abstract}

Key words: cost of reproduction, stage-structures matrix population model, sustainable harvest, conservation of biodiversity.

Résumé : Considérant les effets négatifs potentiels de la production de semences sur la survie et la croissance des plantes adultes, une récolte modérée des fleurs pourrait n'avoir que de faibles effets négatifs sur la croissance des populations de plantes pérennes longivives telles que le Limonium carolinianum. Les auteurs ont examiné cette hypothèse en récoltant des données sur la survie, la croissance et la fécondité d'une population non-récoltée au cours de cinq années, et ont conduit une récolte expérimentale pour en examiner l'effet sur la survie et la croissance des plantes adultes, au cours d'une période de trois ans. Ils ont résumé les résultats sous forme d'un modèle de population matriciel structuré par étapes, incluant un élément stochastique qui incorpore la variation d'année en année dans les probabilités de transition. Contrairement à l'hypothèse originale, les auteurs ont constaté que l'absence de mise à fruit par ablation des fleurs n'augmente ni la survie, ni la croissance des plantes adultes. En déterminant le niveau de récolte qui réduit le taux de croissance de la population à 1.0, les auteurs estiment que le taux de récolte maximale durable est de $16 \%$, soit une valeur qui est environ la moitié des taux de récolte rapportés pour les marais accessibles de la région étudiée. En dépit de cette situation, il est peu probable que les taux de récolte signalés conduisent à l'extinction des populations dans un avenir prévisible. Pourvue que la dimension de la population soit $>100$ et que les taux de récolte soient $<90 \%$, le temps nécessaire à l'extinction dépasse 100 ans. Ceci tient compte du taux très élevé de survie des adultes chez cette espèce et du fait que la récolte est sans effet sur la survie ou la croissance des adultes. Cependant, à cause de la longue phase pré-adulte chez cette espèce ( $8-9$ ans), et du fait que la fécondité des jeunes adultes est faible, le rétablissement après la récolte est extrêmement faible. Sous une récolte intensive, la dimension d'une population peut être réduite à $25 \%$ de sa valeur originale en 7 ans, mais il faudra en moyenne 34 ans de récupération, une fois la récolte arrêtée.

Mots clés : coût de la reproduction, modèle de population par matrice d'étapes structurales, récolte durable, conservation de la biodiversité.

[Traduit par la Rédaction]

Received 14 December 2001. Published on the NRC Research Press Web site at http://canjbot.nrc.ca on 5 August 2002.

J.L. Baltzer, E.G. Reekie, ${ }^{1}$ H.L. Hewlin, and P.D. Taylor. Biology Department, Acadia University, Wolfville, NS B0P 1X0, Canada.

J.S. Boates. Wildlife Division, Nova Scotia Department of Natural Resources, Kentville, NS B4N 4E5, Canada.

${ }^{1}$ Corresponding author (e-mail: ed reekie@acadiau.ca). 


\section{Introduction}

The Convention on Biodiversity and other initiatives have fueled the expectation that the sustainable use of wild plants, animals, and other organisms will play an important role in the conservation of biodiversity (Prescott-Allen and Prescott-Allen 1996; Secretariat of the Convention Biological Diversity 2001). Unfortunately, there are relatively few cases (e.g., Olmsted and Alvarez-Buylla 1995; Maze and Bond 1996) where the biology of a nontraditional species is well enough known to determine if the impacts of harvesting are sustainable. Whereas it is unlikely that we will ever have the benefit of scientific and traditional use information as a planning basis for many species, there is a need for studies that document the impacts of different uses on a variety of diverse organisms. We studied in detail one such activity, the nonregulated commercial harvest of the flowers of sea lavender Limonium carolinianum (Walter) Britton (Plumbaginaceae), a perennial salt marsh herb.

The range of sea lavender includes the east coast of North America from Newfoundland to Texas (Roland and Smith 1983). The species is fairly abundant although patchily distributed on coastal salt marshes. Like many salt marsh species, L. carolinianum populations are threatened with loss of natural habitat from agriculture and erosion (Hatcher and Patriquin 1981). In Nova Scotia, about $43 \%$ of the original salt marsh habitat remains (Hatcher and Patriquin 1981) compared with 35\% elsewhere in the Maritime Provinces (Lands Directorate, Environment Canada 1986). What remains of this unique habitat is fragmented, with many pockets of salt marsh being $<10$ ha in size (Eaton et al. 1994). Limonium carolinianum populations are also under pressure from commercial harvesting. Individual plants bear from 1 to 20 or more inflorescences, which, due to their aesthetic appeal and ease of drying, are frequently used in floral arrangements. The scale of such harvesting has recently increased; a recent Nova Scotia study revealed that on four major marshes the proportion of flower stalks harvested averaged 32\% from 1996 to 1999 on those parts of the marshes within $100 \mathrm{~m}$ of road access (Baltzer et al. 2002). In some years the proportion of flower stalks removed from some marshes approached $100 \%$.

The impact of flower harvesting on L. carolinianum populations is unknown. Baltzer et al. (2002) demonstrated that no seedlings emerge in small $(5 \times 5 \mathrm{~m})$ experimental plots from which flowers were removed the previous year. The rapid and dramatic effect of harvesting on seedling recruitment is a function of the limited dispersal of this species ( $90 \%$ of seedlings emerge within $61 \mathrm{~cm}$ of the parent) and the absence of a seed bank (tethered seed experiments indicate seeds do not survive $>1$ year under field conditions) to buffer year-to-year variation in seed output (see Baltzer et al. 2002). However, the impact of harvesting on seedling recruitment may be of little consequence to the population dynamics of this species. In long-lived perennial plants, variation in seed output may have minimal effects on population growth rate (Caswell 1986; Schmid 1990; Calvo 1993; Maze and Bond 1996). Furthermore, removal of the flowers prevents seed set, and the reallocation of the resources that would have been invested in seed production has the potential to have positive effects on adult survivorship and growth.
Experimentally preventing pollination or flower removal enhances vegetative growth and survivorship in a variety of species (Zimmerman and Pyke 1988; Snow and Whigham 1989; Zimmerman and Aide 1989; Ackerman and Montalvo 1990; Primack and Hall 1990; Fox and Stevens 1991; Ashman 1992; Lehtilä and Syrjänen 1993; Primack et al. 1994). It is conceivable, therefore, that in spite of its detrimental effects on seed output, flower harvesting may have minimal, or even positive, effects on population growth.

Our objective in this study was to examine the demographic consequences of flower harvesting in L. carolinianum. We collected data on growth, survivorship, and reproduction for both unharvested and experimentally harvested individuals in seven size classes over a 4-year period. Experimental harvests were conducted in order to examine resource reallocation in L.carolinianum. Harvested and unharvested data were used to parameterize a stage-structured matrix population model, which was then used to address the following questions. How important is resource reallocation from seed maturation to vegetative growth in reducing the negative impact of flower harvesting on population growth? What is the long-term impact of current harvest levels on population size? What is the maximum sustainable harvest level? How long will it take for a population to recover from overharvesting once harvesting is discontinued? How long will it take for a population of a given size to become extinct if overharvesting continues indefinitely?

\section{Materials and methods}

\section{Study species}

Limonium carolinianum, commonly known as sea lavender, is a long-lived perennial salt marsh herb found in intertidal areas incliding salt marsh and rocky and sandy beach habitats where inundation with seawater occurs frequently. Individuals have leathery, succulent leaves arranged in a basal rosette and attached by a compressed stem to a central, woody taproot. Individuals are capable of limited clonal growth through the addition of ramets to the underground stem. The ramets, however, remain attached to the central taproot and do not give rise to physiologically independent plants. Flowering occurs between July and October producing from 1 to $>20$ branched inflorescences bearing many tiny purple flowers pollinated by insects. Breeding experiments have shown $L$. carolinianum to be self-compatible and wild individuals contain both selfed and crossed seeds (Hamilton and Rand 1996). Each flower generally produces one seed but may produce as many as four. Seed dispersal is generally limited to within an $80-\mathrm{cm}$ radius of the parent plant (Baltzer et al. 2002). Seeds can float for as long as $7 \mathrm{~h}$ (Baltzer et al. 2002) and have been found on the feet and feathers of waterfowl (Vivian-Smith and Stiles 1994), indicating that longer distance dispersal does occur. However, using seed removal experiments, Baltzer et al. (2002) demonstrated that although long-distance dispersal may be important in founding new populations, it is not important to the local population dynamics.

\section{Demographic parameters in an unharvested population}

We studied a population of $L$. carolinianum in the Wolfville salt marsh on the Bay of Fundy coast in Nova Scotia, Canada 
Fig. 1. Life cycle diagram for Limonium carolinianum. Bubbles represent the seven life stages included in the matrix model and arrows represent the transitions among these stages. The numbers beside each transition are the transition probabilities used in model I and, in parentheses, model II.

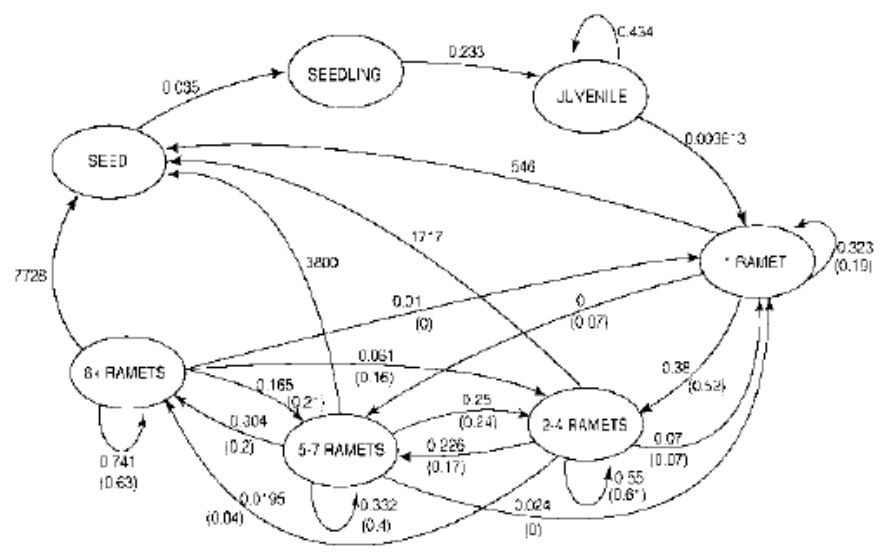

$\left(45^{\circ} 05^{\prime} \mathrm{N}, 64^{\circ} 21^{\prime} \mathrm{W}\right)$. The area sampled was $>500 \mathrm{~m}$ from the nearest road where previous work had revealed that harvest levels were minimal (Baltzer et al. 2002). During the course of the study, no evidence of harvesting (e.g., remains of cut flower stalks) was observed. All individuals sampled were classified into one of seven life stages (Fig. 1): seeds, seedlings (individuals $<1$ year of age), juveniles (individuals $>1$ year of age that have not yet reproduced), and four adult stages, 1 ramet, 2-4 ramets, 5-7 ramets, and $8+$ ramets. We measured the following parameters.

\section{Seedling survivorship}

We randomly selected 20 points along the high water mark (an old dyke) and established a transect from each point to water at low tide. We then randomly selected a point along each of these 20 transects and established a $15 \times$ $15 \mathrm{~cm}$ plot in the patch of seedlings that was closest to this point. In each year from 1996 to 1999 , we monitored all seedlings in each plot by putting a small coloured wire loop at the base of each plant. The total numbers of monitored seedlings were $795,98,158$, and 184 in 1996, 1997, 1998, and 1999 , respectively. Seedlings were observed weekly throughout the growing season and surviving seedlings labelled with numbered metal tags when judged to be of sufficient size. The following spring (May), we revisited every plot and scored remaining seedlings as alive or dead.

\section{Juvenile survivorship and growth}

We continued to monitor all marked seedlings by conducting a census every year until May 2000. After the first year, surviving seedlings in the immediate neighbourhoods of each of the 20 seedling plots were tagged in the fall to increase the size of the marked cohort. This resulted in a total of 44, 96, and 162 new juveniles (i.e., 1-year-old plants) being tagged in 1997, 1998, and 1999, respectively.

The proportion of juveniles that make the transition to the reproductive category each year was calculated indirectly, as only one of our marked juveniles labelled in the first year of the study flowered over the 4 years of this study. First, we estimated the juvenile growth rate by counting the number of leaves on plants in the three age cohorts in August 1999.
After testing for curvilinearity, a linear function was fitted to the leaf number/plant age data by means of least squares regression. The slope of this line provided the yearly growth rate. Second, we estimated the minimum size required for reproduction by determining leaf number and whether or not the plant had flowered in a random sample of 169 one-ramet plants in August 1999. Third, using the growth rate data, we determined how many years it would take for a new juvenile to reach the minimum size required for reproduction. Finally, using the juvenile survivorship data, we calculated what proportion of a cohort of new juveniles survives until the plants reach reproductive size.

\section{Adult survivorship, growth, and reproduction}

We uniquely marked 90 adult plants with wooden stakes in May 1996 and a further 70 adult plants in May 1997. Plants were selected to provide roughly equal representation of the four adult stages. In the spring of each year from 1996 to 2000 , we determined whether a plant was alive or dead. If the plant was alive, we counted the number of ramets, which was later used to determine transition probabilities among stages. At the end of each growing season, we counted the number of flower stalks on each plant.

\section{Fecundity}

The flower stalks of five 1 ramet, eleven 2-4 ramet, seven 5-7 ramet, and four 8+ ramet plants were collected after seed set in the fall of 1998 and the number of seeds per flower stalk and per plant counted.

\section{Seed germination}

In the spring of 1999 and 2000, immediately after seedling emergence had ended, we estimated probability of successful seed germination by counting the number of seedlings that emerged around 10 of the marked adult plants. We selected plants that were $>3 \mathrm{~m}$ from any other adult plant to avoid the possibility of overlapping seed shadows. Circular, 2-cm-wide belt transects were set up at $10-\mathrm{cm}$ intervals from the mother plant and the total number of seedlings in each transect counted. Sampling continued outwards from the mother plant until we sampled three consecutive transects without seedlings. Seedling density for each band was calculated. To estimate the number of seedlings in each of the intermediate bands, the seedling densities of the two adjacent bands were averaged and this value multiplied by the total area of the band in question. The sum of the values for all bands provided the number of seedlings surrounding the plant. An earlier study found that seeds of this species do not survive for more than 1 year (Baltzer et al. 2002), so we assumed that all seedlings resulted from seed produced the previous year. All the plants surveyed were also part of the adult demography study described above, so the number of flower stalks produced by each plant was known from the previous year's survey. We thus obtained an estimate of the previous year's seed production for each plant by multiplying the number of flower stalks by our estimate of the average number of seeds per flower stalk (see above). By comparing the total number of seedlings with the expected number of seedlings given the reproductive output of each plant from the previous year, we estimated the transition from seed to seedling. 


\section{Stage class distribution}

The stage distribution vector for the Wolfville salt marsh in 1999 (see below) was calculated as follows. Circular plots (1-m radius) were first established around 112 randomly selected points. Any plant that we observed above the thatch that was in bloom or bore flower stalk scars from previous years was classified as an adult; others were classified as juveniles. The total number of ramets and flower stalks were recorded for each plant. Within each plot, two $15 \times 15 \mathrm{~cm}$ subplots were randomly established and the number of small juvenile plants beneath the thatch counted. The total area sampled was determined and estimates of the number of plants currently in each stage category were made for the entire study area (area $=7.3 \mathrm{ha}$ ). The total number of seedlings on the marsh was determined by multiplying the average number of seedlings produced per plant (of a given size class) by our estimate of the total number of plants of that size class on the marsh (see above) and summing.

\section{Effect of harvesting on survivorship and growth}

One hundred and eighty adult plants were selected and tagged in 1996. Sixty of these were randomly designated as controls. The remaining 120 had their flower stalks removed at or before full bloom each year from 1996 to 1998. In 1997, an additional 70 control plants were added. In May of 1996-1999, we counted the total number of ramets on each plant. The effect of harvesting on survivorship was assessed using a two-tailed Fisher's exact test to examine the proportion of the original 180 plants that died in the harvested versus control treatments at the end of the 3-year period. The effect of harvesting on number of ramets in any one year was assessed by analysis of covariance with treatment (whether or not flowers were removed) as the single classification variable and number of ramets in the previous year as a covariate.

\section{Matrix population model}

Using the above data, we parameterized a stage structured matrix population model with seven life stages: seed, seedling, juveniles, 1 ramet adults, 2-4 ramet adults, 5-7 ramet adults, and 8+ ramet adults. Survivorship, growth, and fecundity for each stage were summarized in the form of a population projection matrix (Caswell 1989). The diagram (Fig. 1) shows all possible stage transitions.

The results of the stage class distribution survey (see above) were used to construct the initial stage distribution vector for the population. The seven rows in this vector contained the number of individuals found in each of the seven growth stages for the Wolfville population.

Three different versions of the matrix model were constructed. Model I had a population projection matrix in which the transition probabilities were the average (across years) values for the unharvested control plants. Fecundities either were the average values or were set to some fraction of these values to simulate different harvest levels. Model II set the fecundities to zero and used the average transition probabilities for the experimentally harvested plants. Model III was a stochastic version of the first model; the fecundity and transition probabilities for a particular stage were randomly selected from among the estimates for individual years for each iteration of the model. The random selection process was limited in that entire columns within the matrices were selected rather than individual probabilities to avoid the possibility of having the probabilities for a given stage sum to a value $>1$. These three models were used in a series of experiments to assess the impact of flower harvesting on population dynamics and how this impact may be modified by taking into consideration the cost of seed production and by variation in population size.

\section{Experiment 1. Importance of fecundity in determination of population growth rate}

Stage-specific sensitivity and elasticity analyses (Caswell 1978) were conducted on the version of model I that included the observed fecundities for the control plants. Sensitivity analyses measure the impact of small changes of a transition probability on the growth rate of the population (Caswell 1989). In other words, the magnitude of the sensitivity value for a given transition indicates its importance to the population growth rate. Elasticity analyses, on the other hand, measure the proportional contribution of a transition probability to growth rate (de Kroon et al. 1986) (formulae used in calculation of elasticities and sensitivities are presented in the Appendix).

\section{Experiment 2. Cost of seed maturation and its role in mitigating the impact of flower harvesting}

After setting fecundity to zero in model I as well as in model II, the dominant eigenvalue of each projection matrix was determined as an estimate of population growth rate. Predicted population size over a 30-year time period was also determined for both models through repeated multiplication of the projection matrix and stage distribution vector. The version of model I used in this exercise represents a population that is subjected to $100 \%$ harvest, yet still retains the transition probabilities of the control population from which flowers were not removed. Model II, on the other hand, is based on the empirical data from the experimental population from which all flowers were removed. Therefore, the transition probabilities in this model incorporate the potential benefits of not having to allocate resources to seed maturation. As a result, the predictions of these two models provide a measure of the error involved in failing to consider the benefits of not producing seeds in predicting the longterm effects of flower harvesting.

\section{Experiment 3. Maximum sustainable level of flower harvesting}

For the purposes of this study, the maximum sustainable harvest was defined as that level that resulted in neither an increase nor a decrease in projected population size over time (Olmsted and Alvarez-Buylla 1995). To determine this level, the fecundities in Model I were reduced to that percentage of their original value that resulted in a growth rate of 1 for the population projection matrix. This procedure assumes that harvesting impacts all stages equally, i.e., it assumes that harvesters do not target particular stages for flower collection. This is fairly realistic given that a single harvester will focus on a localized patch within a marsh which they will harvest almost entirely (including smaller adult stages; personal observation). 


\section{Experiment 4. Future impact of current harvest levels}

A previous study (Baltzer et al. 2002) found that in the study area, harvesters on average remove about $30 \%$ of the flowers on easily accessible marshes but in some instances may remove more than $90 \%$. The projected impact of these observed harvest levels on population size was determined using model III. For this exercise, the fecundities of the various stages were either unmodified (no harvest) or reduced by 30,60 , or $90 \%$ to simulate harvesting without changing any other aspect of the projection matrix. Each of the four projection matrices was then repeatedly multiplied by the stage distribution vector to obtain population size over a 30 year time period at each harvest level.

The time required for a population to recover from overharvesting was also examined. The population was reduced to 25,50 , and $90 \%$ of its original size through repeated iterations of the model with $100 \%$ harvest. Once the appropriate reduction was achieved, the model was returned to the unharvested state and the number of iterations required to return the population to preharvest size determined.

Model III was also used to estimate population extinction times for harvest levels ranging from 30 to $100 \%$. Starting with an initial population size of $10,100,1000$, or 10000 adults, the projection matrices were repeatedly multiplied by the stage distribution vector until population size declined to zero. A population size of 10 represents the typical size of an isolated patch of L. carolinianum within a marsh, while a population size of 10000 represents the total population in a relatively large marsh (assuming the same population density as observed on the marsh in the present study and a marsh size of $10 \mathrm{ha}$ ). Due to loss of salt marsh through agricultural dyking and erosion caused by dredging and filling, much of the remaining salt marsh in Nova Scotia is highly fragmented with many of the pockets being $<10$ ha in size (Eaton et al. 1994).

As model III had a stochastic element, all of the above exercises were repeated 20 times and the data summarized by taking the mean and standard deviation.

\section{Results}

\section{Survivorship, growth, and reproduction in an} unharvested population

There were apparent differences in survivorship among the seven growth stages with survivorship generally increasing as the size and (or) age of the plants increased (Fig. 2). There was significant year-to-year variation in the survivorship of seeds and seedlings but not in any of the later stages.

The number of leaves in juvenile plants increased in a linear fashion with plant age $(y=2.14+0.45 x, p=0.0046)$; however, there was a great deal of scatter in the data $\left(r^{2}=\right.$ 0.093). There was no indication that the rate of growth changed with age; a quadratic term fit to the linear regression of leaf number versus time was not significant. The size distribution of one-ramet plants revealed that no plants with fewer than five leaves flowered and all plants with eight leaves flowered. The percentages of plants with five, six, and seven leaves that flowered were 32,58 , and $87 \%$, respectively. For the purposes of subsequent calculations, we assumed that plants flowered for the first time (i.e., they became adults) when they had six leaves. Using the above
Fig. 2. Stage-specific yearly survivorship from 1996 to 1999 for Limonium carolinianum on the Wolfville salt marsh.

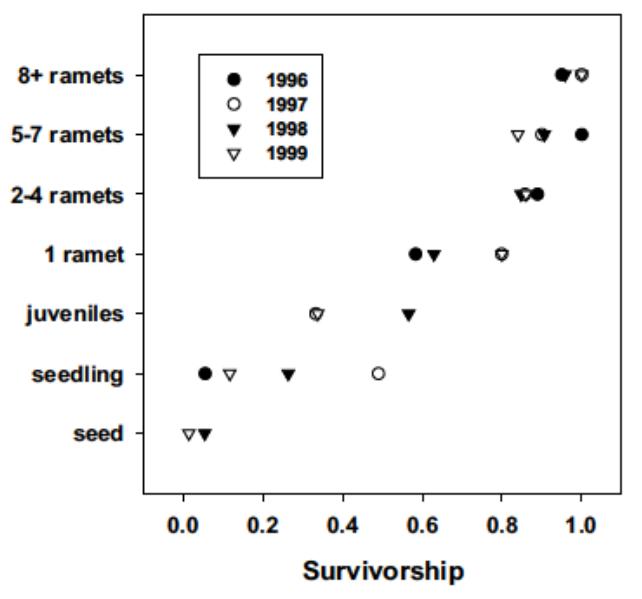

equation that describes the increase in number of leaves over time, we estimated the age of these plants to be somewhere between 8 and 9 years. Using the average yearly survivorship of juveniles (0.433) and assuming that all juveniles flower when 8 years of age produced an estimate of 0.00375 (i.e., $0.433^{(8-1)}$ ) for the transition from the juvenile to the adult category.

One-ramet adults that survived had one of two fates: they either remained in this category (i.e., they did not increase in size) or they increased in size to the 2-4 ramet category the subsequent year. The proportion of these plants that increased in size varied from year-to-year ( $p=0.0035$, Fisher's exact test). Plants in the $2-4$ ramet category that survived had one of four fates: they could decrease in size and go into the 1 ramet category, remain in the 2-4 ramet category, increase in size and enter the 5-7 ramet category, or, in a few cases, increase sufficiently in size to enter the $8+$ ramet category. There was no significant year-to year variation in fate of individuals in the 2-4 ramet category ( $p=$ 0.7816 , Fisher's exact test). Surviving individuals in the 5-7 ramet category also experienced one of four fates: they could increase in size and enter the $8+$ ramet category, remain in the 5-7 ramet category, or decrease in size to either the 2-4 or 1 ramet category. There was no significant variation among years in these probabilities $(p=0.1650$, Fisher's exact test). Surviving individuals in the $8+$ ramet category either remained in this category or decreased in size to enter the $5-7,2-4$, or 1 ramet categories. Once again, there was no significant variation among years in these probabilities ( $p=0.2163$, Fisher's exact test).

There were marked differences among the four adult growth stages in the number of seeds produced by flowering individuals, the number of seeds increasing by an order magnitude between the smallest and largest stages (Fig. 3A). There were also apparent differences among growth stages in the probability of flowering in any one year, the 1 ramet stage having a much lower chance of flowering relative to the other three stages in all 5 years of the study (Fig. 3B). There was no evidence that there was any significant amongyear variation in the probability of flowering $(p>0.05$ for the effect of years in all four stages, Fisher's exact test). 
Fig. 3. (A) Stage-specific fecundity of those Limonium carolinianum individuals that flower and (B) the proportion of those individuals in the adult size classes that flowered in the years 1996-2000.
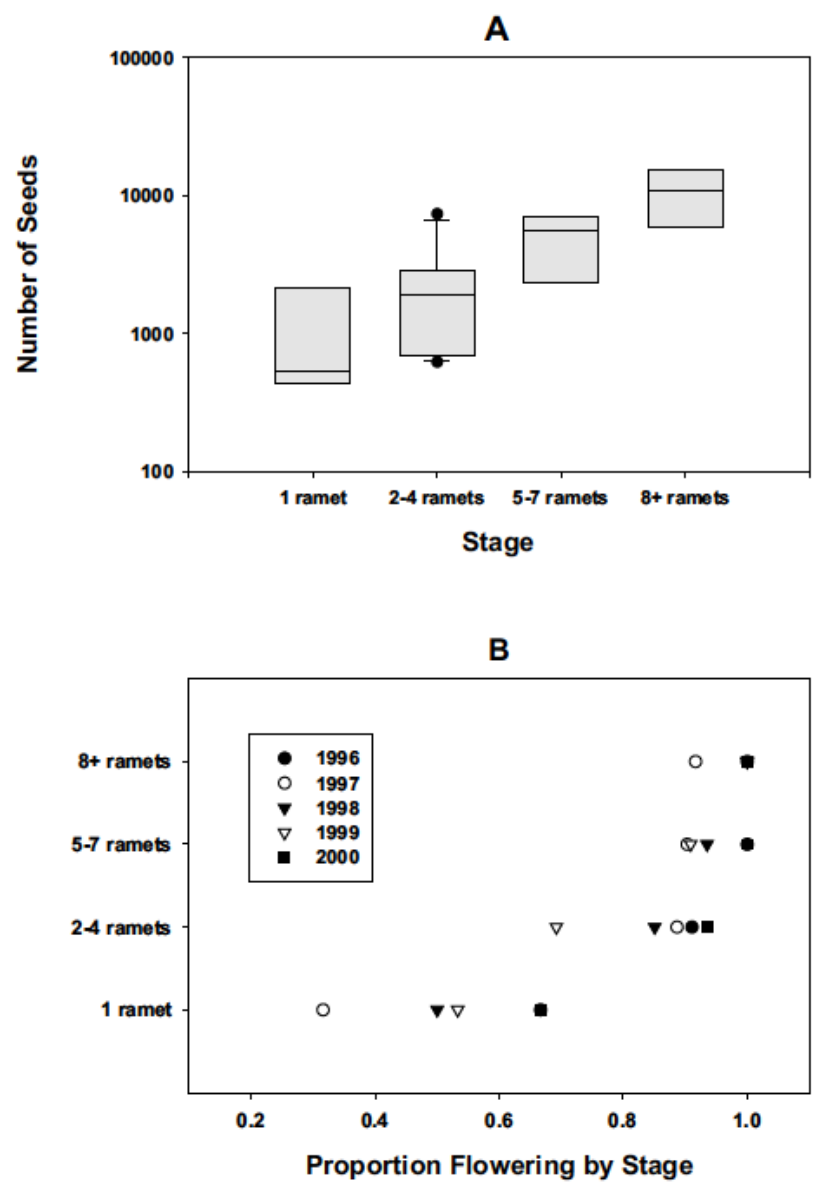

Table 1. Stage class distribution of Limonium carolinianum on the Wolfville salt marsh in August 1999.

\begin{tabular}{lc}
\hline Stage class & Number of individuals \\
\hline Seedling & 123457 \\
Juvenile & 118938 \\
1 ramet & 1710 \\
2-4 ramets & 3231 \\
5-7 ramets & 719 \\
8+ ramets & 1373 \\
\hline
\end{tabular}

\section{Distribution of life stages in the study population}

The greatest number of individuals was found in the seedling stage followed closely by the juvenile stage (Table 1). Seedling and juvenile stages outnumbered the adult stages by two orders of magnitude. Among the four adult categories, the 2-4 ramet category was the largest.

\section{Effect of harvesting on subsequent survivorship and growth}

Whether or not flowers were removed from a plant had no impact on subsequent survivorship ( $p=0.614$, Fisher's exact
Fig. 4. Effect of experimental flower removal on plant size (number of ramets) in Limonium carolinianum for (A) 1996, (B) 1997, and (C) 1998. Solid symbols represent control plants and open symbols represent plants from which flowers were removed at or before full bloom.
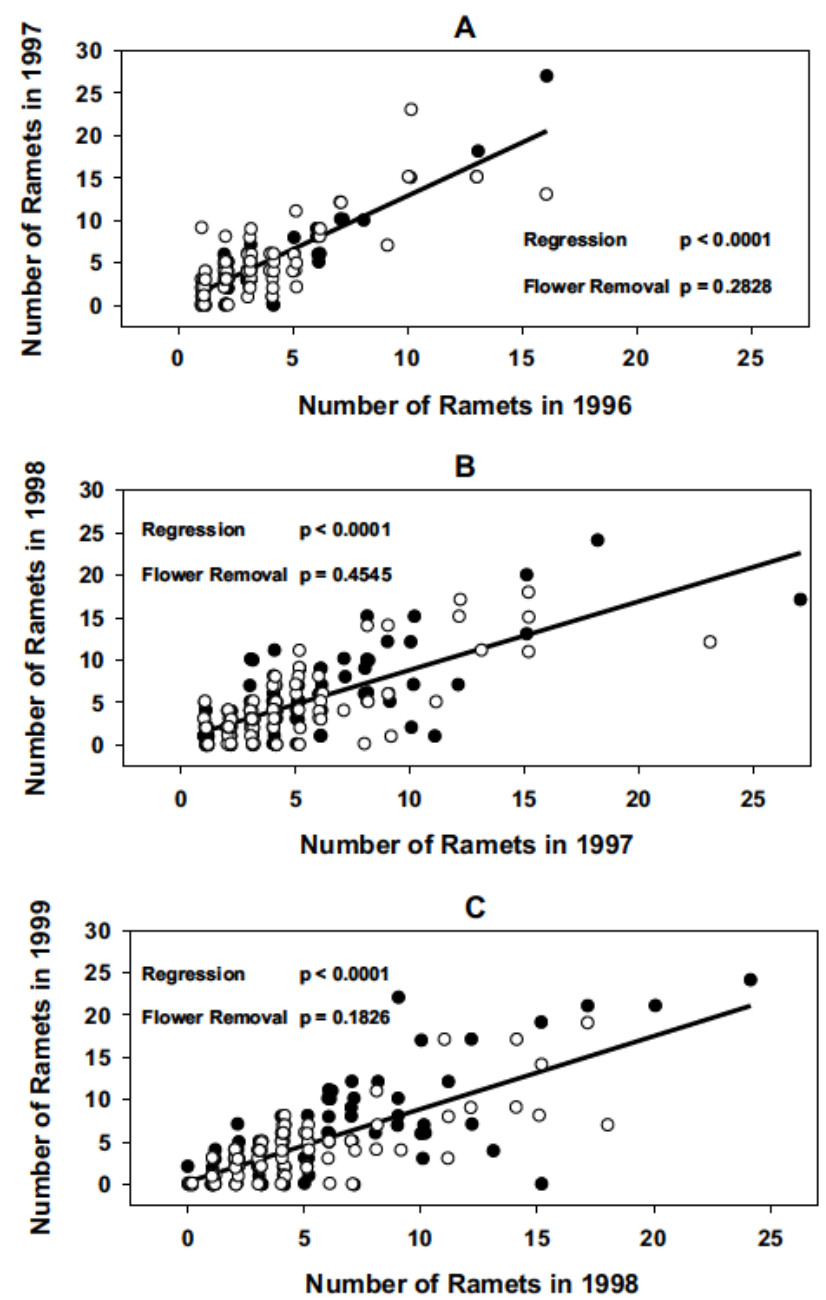

test). Sixty-five percent of the control plants (39/60) survived to the end of the 3-year experimental period compared with $69 \%(83 / 120)$ for the plants from which flowers were removed. Even after correcting for differences in initial size (analysis of covariance, Table 2), there were no effects of flower removal on the number of ramets produced the following year regardless of year of study (Fig. 4).

\section{Model predictions}

Sensitivity analyses performed on the unharvested version of model I revealed that variation in the transition from the juvenile to adult stage had the greatest impact on population growth rate (Table 3). The value for this transition (16.4) was substantially larger than any of the other values. The next highest value (1.7) was for the seed to seedling transition. The third highest value $(0.46)$ was for the $2-4$ ramet to $8+$ ramet transition, but this value was similar in magnitude to many other transitions in the matrix. The lowest sensitivities were for the various reproductive transitions, values for which ranged between $3.1 \times 10^{-6}$ and $6.7 \times 10^{-6}$. 
Table 2. Analysis of covariance for the relationship between plant size (number of ramets) in year $t$ and plant size in year $t-1$ as affected by treatment (harvested versus unharvested) for Limonium carolinianum for the period from 1996 to 1999.

\begin{tabular}{llrrl}
\hline Dependent variable & Source & df & $\begin{array}{c}\text { Sum of } \\
\text { squares }\end{array}$ & $\begin{array}{l}\text { Level of } \\
\text { significance }\end{array}$ \\
\hline Ramets 1997 & Model & 2 & 1936.12 & 0.0001 \\
& Ramets 1996 & 1 & 1930.13 & 0.0001 \\
& Treatment & 1 & 5.98 & 0.2828 \\
Ramets 1998 & Error & 147 & 756.58 & \\
& Model & 2 & 2024.17 & 0.0001 \\
& Ramets 1997 & 1 & 2019.55 & 0.0001 \\
Ramets 1999 & Treatment & 1 & 4.62 & 0.4545 \\
& Error & 199 & 1635.71 & \\
& Model & 2 & 2523.56 & 0.0001 \\
& Ramets 1998 & 1 & 2506.87 & 0.0001 \\
& Treatment & 1 & 16.70 & 0.1826 \\
& Error & 186 & 1735.08 & \\
\hline
\end{tabular}

Table 3. Results of sensitivity analysis on model I.

\begin{tabular}{llllllll}
\hline & Seed & Seedling & Juvenile & 1 ramet & $2-4$ ramets & $5-7$ ramets & $8+$ ramets \\
\hline Seed & - & - & - & $5.17 \times 10^{-6}$ & $6.65 \times 10^{-6}$ & $3.09 \times 10^{-6}$ & $4.21 \times 10^{-6}$ \\
Seedling & 1.71119 & - & - & - & - & - & - \\
Juvenile & - & 0.00082 & 0.1031 & - & - & - & - \\
1 ramet & - & - & 16.3624 & 0.103543 & 0.13301 & 0.061932 & 0.084236 \\
2-4 ramets & - & - & - & 0.246181 & 0.229793 & 0.106996 & 0.145529 \\
5-7 ramets & - & - & - & & 0.334349 & 0.155679 & 0.211744 \\
8+ ramets & - & - & - & - & 0.458643 & 0.213552 & 0.29046 \\
\hline
\end{tabular}

Note: Values represent the impact of small changes in a transition probability on population growth rate of Limonium carolinianum.

Table 4. Results of elasticity analysis on model I.

\begin{tabular}{llllllll}
\hline & Seed & Seedling & Juvenile & 1 ramet & 2-4 ramets & 5-7 ramets & 8+ ramets \\
\hline Seed & - & - & - & 0.00281 & 0.01491 & 0.01168 & 0.032315 \\
Seedling & 0.058729 & - & - & - & - & - & - \\
Juvenile & - & 0.00019 & 0.0444 & - & - & - & - \\
1 ramet & - & - & 0.05873 & 0.03319 & 0.00924 & 0.00151 & 0.000837 \\
2-4 ramets & - & - & - & 0.09305 & 0.12548 & 0.02668 & 0.008795 \\
5-7 ramets & - & - & - & & 0.07492 & 0.05134 & 0.034708 \\
8+ ramets & - & - & - & - & 0.00889 & 0.06452 & 0.213887 \\
\hline
\end{tabular}

Note: Values represent the proportional contribution of a transition probability to population growth rate of Limonium carolinianum.

The elasticity analysis indicated that transitions among the various adult growth stages contributed the most to the overall population growth rate (Table 4$)$. The three highest elasticities were for the transitions from the $8+$ to $8+$ ramet categories (0.213), the 2-4 to 2-4 ramet categories $(0.125)$, and the 1 to $2-4$ ramet categories (0.093). The lowest elasticity was for the seedling to juvenile transition (0.00019). The reproductive transitions were also relatively low. The elasticities for the adult to seed transitions ranged between 0.0323 and 0.0617 , the value of the elasticity increasing as the size of the plant increased.

The average transition probabilities used in model I (unharvested) and model II (harvested) are presented in
Fig. 1. Harvesting resulted in both increases and decreases in growth and (or) survivorship depending on the particular growth stage examined. The population growth rate of model I was slightly above 1 (1.007), indicating that the unharvested population was increasing slowly in size. Reducing fecundities to zero in model I to simulate a $100 \%$ harvest reduced the population growth rate to 0.916 . The population growth rate of model II, which also assumed a $100 \%$ harvest but used the transition probabilities of the experimentally harvested plants, reduced the growth rate to 0.908. In other words, the net effect of considering the impact of flower removal on adult growth and (or) survivorship was a further decrease in population growth, 
but the overall effect was small (the length of time it would take to reduce population size to $90 \%$ of its original size is 27 and 26 years for models I and II, respectively).

The level of harvest that reduced the population growth of model I to 1.0 was $16 \%$. Model III, the stochastic version of model I, suggests that a harvest level of $30 \%$ will on average result in a $16 \%$ decline in population size after 30 years (Fig. 5). However, the model also suggests that a decline of this magnitude could potentially be masked by the stochastic year-to-year variation in growth, survivorship, and fecundity. Harvest levels of 60 and $90 \%$ resulted in much more marked declines in population size that could not be masked by year-to-year variation (Fig. 5). After 30 years, medium and high harvest levels lead to declines of 53 and $85 \%$, respectively.

Simulations suggest that $L$. carolinianum populations will not recover quickly from overharvesting (Table 5). Using model III and assuming that all flowers were harvested, the time required to reduce population size to 25,50 , and $90 \%$ of its original value was determined to be $6.7,10.5$, and 29.4 years, respectively. The average time required to recover from these declines assuming no harvesting was 33.8, 49.8, and 144.4 years, respectively, but with a great deal of variation (Table 5). A 25\% reduction in the population could occur in as few as 6-8 years with subsequent recovery taking from 7 to $>100$ years.

Although L. carolinianum populations may be slow to recover, harvesting is unlikely to drive populations to complete extinction (Fig. 6). Simulations with model III suggest that even with $100 \%$ harvest every year and a population size of only 10 adults (i.e., the size of an isolated patch within a marsh), it took almost 30 years for extinction to occur. When the adult population size was increased to 10000 (i.e., total population in a 10-ha marsh), it took more than 100 years. Decreasing the level of harvest from $100 \%$ resulted in exponential increases in the length of time required for extinction.

\section{Discussion}

The elasticity analysis suggested that given our current estimates for the various transitions in the model, adult survivorship and growth are more influential in determining growth rate than fecundity. The analysis also suggested that the fecundity of large individuals is much more important than that of smaller individuals. The first conclusion is a direct consequence of the low survivorship of the juvenile stages versus the high survivorship of the adult stages, while the second conclusion reflects the greater likelihood of flowering in large individuals and their very high reproductive output when flowering occurs. Collectively, these two conclusions suggest that removal of flowers by harvesters will have relatively little impact on population growth, particularly if their removal enhances adult survivorship and growth and increases the number of individuals in the larger size classes. The very low values for fecundity in the sensitivity analysis that examines how changes in the transition probabilities affect growth rate also support this conclusion. We caution, however, that the sensitivity analysis also suggests that the model is very sensitive to changes in the transition from the juvenile to 1 ramet stage and to a lesser extent
Fig. 5. Effect of 30,60 , or $90 \%$ flower removal on predicted population size of Limonium carolinianum on the Wolfville salt marsh over a 30 -year time period. Individual points represent the mean ( $\pm 1 \mathrm{SD})$ of 20 simulations using model III.
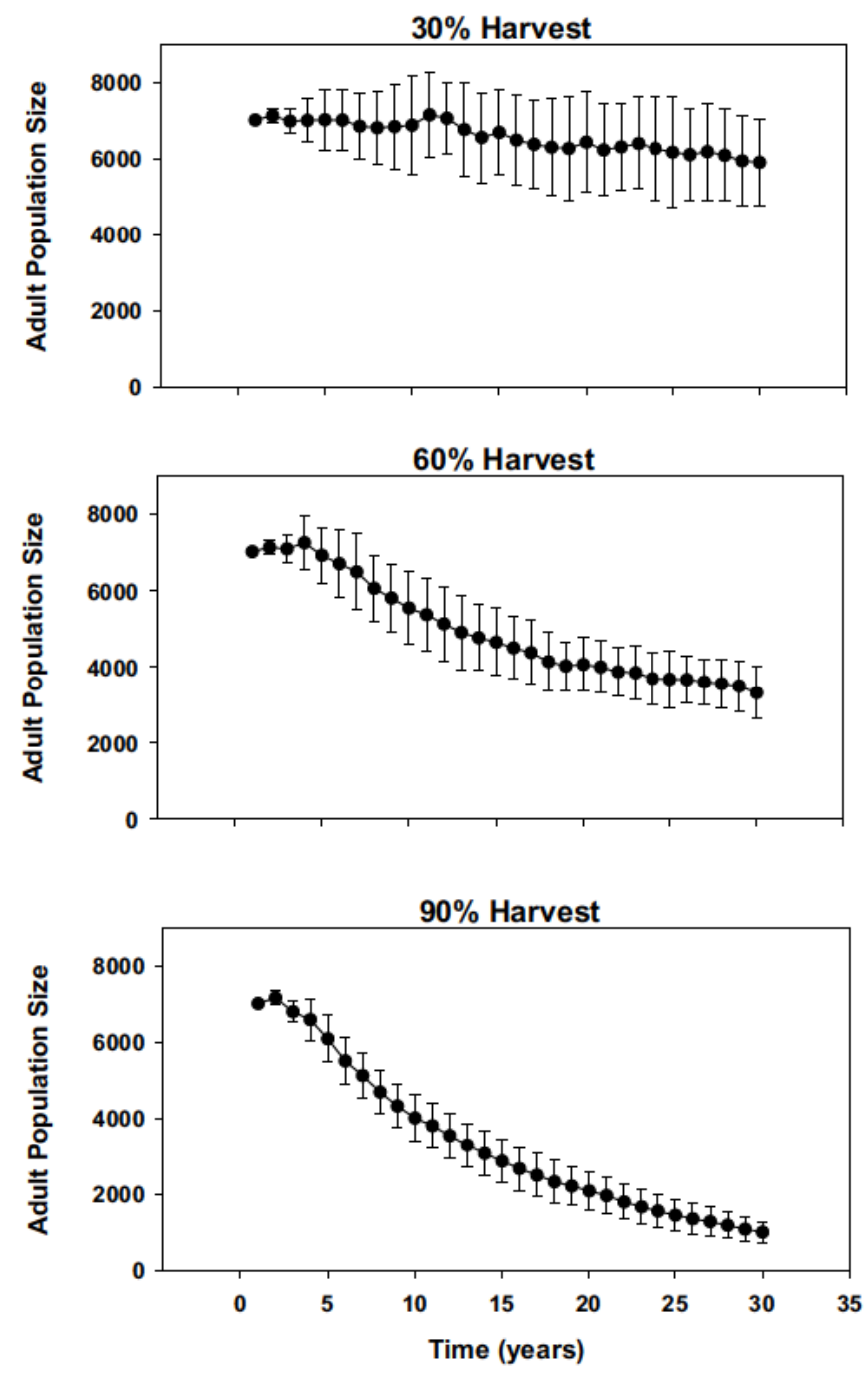

changes in the seed to seedling transition. Our estimates for most of the transitions in the model were based on 4 years of data, and for some transitions, we had 5 years of data. However, the juvenile to 1 ramet transition was the one value we estimated indirectly through extrapolation of juvenile growth rates, and the transition from seed to seedling was based on only 2 years of data. If our estimates of these two parameters are incorrect, it could have a major impact on our conclusions. Absolute values and rank orders of elasticity values have been shown to shift with variation in vital rates (Mills et al. 1999; Wisdom et al. 2000). One must also be aware of possible spatial variation in vital rates. In the present study, demographic parameters were obtained from a population on a single salt marsh. If differences among marshes are substantial, this would also have an impact on our conclusions.

The above analysis suggests that there is potential for flower removal to have positive effects on population growth depending on the extent to which removal increases adult survivorship and growth. However, we found no experimental evidence that removal had any significant effect on either 
Table 5. Time in years to a 25,50 , or $90 \%$ reduction in adult population size of Limonium carolinianum assuming $100 \%$ harvest and subsequent recovery times assuming no further harvest.

\begin{tabular}{llll}
\hline & $25 \%$ reduction & $50 \%$ reduction & $90 \%$ reduction \\
\hline Time to reduction & $6.7 \pm 0.98$ & $10.5 \pm 1.54$ & $29.35 \pm 2.24$ \\
Maximum time & 8 & 13 & 35 \\
Minimum time & 5 & 7 & 24 \\
Time to recovery & $33.75 \pm 24.69$ & $49.8 \pm 25.34$ & $144.4 \pm 39.47$ \\
Maximum time & 103 & 103 & 267 \\
Minimum time & 7 & 19 & 89 \\
\hline
\end{tabular}

Note: Values represent the mean $( \pm 1 \mathrm{SD})$ of 20 simulations.

Fig. 6. Effect of harvest level and population size on time to extinction in Limonium carolinianum. Individual points represent the mean $( \pm 1 \mathrm{SD})$ of 20 simulations using model III.

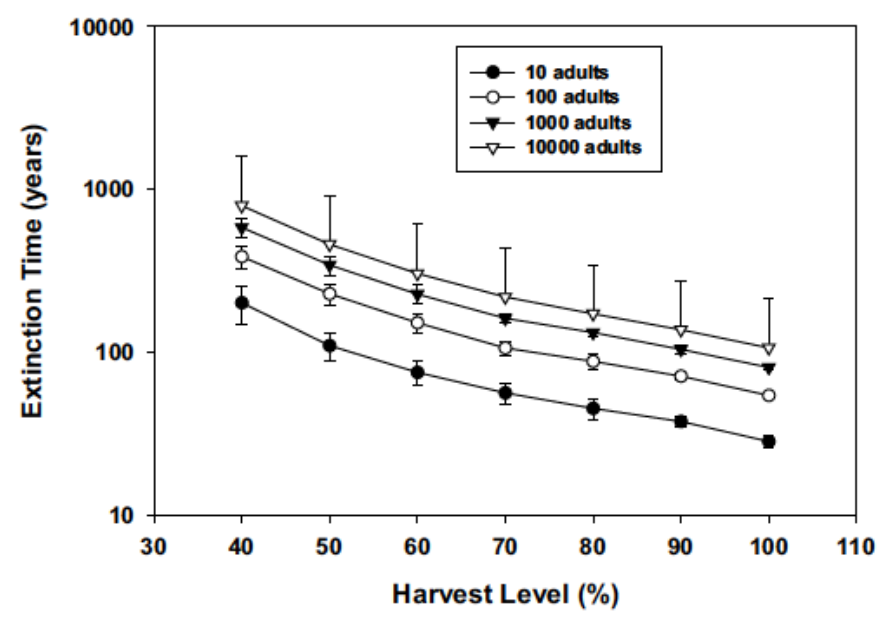

survivorship or growth. In fact, the net effect of the nonsignificant changes in survivorship and growth was a marginal decrease in population growth. While the conclusion that flower removal had no benefit for adult survivorship and (or) growth may seem surprising, there are many other studies that have also been unable to detect any cost associated with reproduction in a variety of different species and in a wide range of different environments (Horvitz and Schemske 1988; Karlsson et al. 1990; Jennerston 1991; Pfister 1992; Calvo 1993; Westley 1993; Galen 1994; Jackson and Dewald 1994; Lehtilä and Syrjänen 1995; Cunningham 1997; Ramsey 1997). In those studies that do detect costs associated with seed production, these costs are often only apparent when plants are subjected to stress or limited resource availability (Syrjänen and Lehtilä 1993; Ågren and Willson 1994; Primack et al. 1994; Thoren et al. 1996; Reekie 1998). The failure of some studies to detect the costs associated with reproduction may be due, at least in part, to the methodological problems associated with measuring these costs (Reznick 1985; Bailey 1992). This is particularly true when costs are measured in terms of genetic trade-offs, as there is often insufficient genetic variation within a population to accurately assess the cost. However, this is not true when, as in the present study, costs are assessed experimentally at the phenotypic level where there is a great deal of power to detect reproductive trade-offs (Reekie 1998). The failure of these studies to detect costs suggests that the cost is relatively low in the particular spe- cies and environment being studied, perhaps because different resources limit seed maturation and vegetative growth (Willson 1983). Alternatively, it is possible that we were unable to detect reproductive costs simply because most of the cost was associated with the production of the flower stalk and the cost of seed maturation was negligible. In most species, however, the opposite is the case, i.e., the cost of flower production is negligible compared with the cost of seed maturation (Willson 1983). It is also conceivable that the removal of the flower stalks wounded the plants and this damage counteracted any potential benefit accruing from not producing seed. However, there were no visible signs of damage (e.g., infection by pathogens) associated with the removal of the flower stalks.

Even though flower removal does not appear to increase adult survivorship in $L$. carolinianum, the fact that fecundity has relatively little impact on population growth rate suggests that the impact of flower harvesting on population size may still be minimal. This suggestion, however, is at odds with the rapid initial decline in population size when harvesting was simulated. On the other hand, the model also predicted that after 10 years or so the rate of decline would slow. Further, the model predicted very long extinction times even at high harvest levels and very small population sizes. These apparently contradictory findings can be reconciled by considering the life cycle of this species and the resulting population size structure. Limonium carolinianum has a prolonged prereproductive or juvenile phase. We estimated that on average, individuals spend 8 years as juveniles. When individuals do reach adulthood, reproductive output is relatively low until they move into the larger size categories where there is a dramatic increase in seed production. As a result, a normal population has a size structure that is strongly dominated by the smaller and (or) younger stages. These are also the stages with the highest mortality. Therefore, when harvesting is first imposed, total population size drops quickly as the smaller and (or) younger individuals die but are not replaced by new recruits. Then, as the population comes to be dominated by larger and (or) older individuals with very high survivorship, the rate of decline slows. Given that these large and (or) old individuals not only have a high survivorship but also the highest fecundity, it means that extinction is unlikely unless the level of harvest is extremely high and population size very small. The prolonged juvenile phase, however, also means that recovery from harvesting will be extremely slow. If harvesting is terminated, even though there may be large adults in the population with high fecundity, it will be 8 years before any of 
their offspring are ready to reproduce. Further, as small oneramet adults, their fecundity will be relatively low until they increase in size and enter the large size classes. It must also be remembered that there was a great deal of year-to-year variation in the survivorship of seeds and seedlings and in the growth of the smallest adult size class. Therefore, recovery could be further delayed by normal environmental fluctuation.

Although the model suggests that the levels of flower harvesting that have been observed in Nova Scotia (Baltzer et al. 2002) will not drive $L$. carolinianum populations to extinction in the foreseeable future, this does not mean that active management of the resource is unnecessary. The model predicts that the maximum sustainable harvest is $16 \%$. The average observed harvest level on easily accessible marshes on the Bay of Fundy is about twice this value. It is true that the model also predicts that a $30 \%$ harvest would result in a relatively slow decline that could easily be overwhelmed by natural fluctuations in growth, survivorship, and fecundity. However, the extremely long recovery times dictate that population size be monitored closely and harvest levels adjusted accordingly to prevent any significant decline. Our results suggest that a $25 \%$ decline in population size could occur in as few as 7 years, while it would take 34 years on average to recover from this decline assuming all harvesting was banned. If for no other reason than to maximize the number of flower stalks harvested, it makes sense to prevent such population declines. It should also be noted that although the average levels of harvesting that have been observed in Nova Scotia may not drive populations to extinction, the actual harvest level in a particular marsh may differ substantially from this average value. In our earlier study (Baltzer et al. 2002), the highest harvest level was observed on the marsh closest to the province's major urban center and in one year approached $100 \%$ removal. In more heavily populated areas, high harvest levels might occur more frequently than would be the case on the Bay of Fundy. In Rhode Island, for example, L. carolinianum has received protected status, which would suggest that harvest levels in this area were high enough to cause serious population declines.

The harvesting of native wild flowers is a significant industry that could be used to help preserve shrinking areas of natural habitat (IUCN 2000). In Australia, for example, the estimated size of the native flower harvest is $\$ 85$ million (FECA 1995). It is vital, however, that this resource is managed in a sustainable fashion. Our study demonstrates that we cannot simply assume on the basis of the presumed trade-off between seed production and growth that flower harvesting in perennial plants is a low-impact use. However, it also demonstrates that this resource can be managed in a sustainable fashion.

\section{References}

Ackerman, J.D., and Montalvo, A.M. 1990. Short- and long-term limitations to fruit production in a tropical orchid. Ecology, 71: 263-272.

Ågren, J., and Willson, M.F. 1994. Cost of seed production in the perennial herbs Geranium maculatum and G. sylivaticum: an experimental field study. Oikos, 70: $35-42$.

Ashman, T.L. 1992. Indirect costs of seed production within and between seasons in a gynodioecious species. Oecologia, 92: 266-272.

Bailey, R.C. 1992. Why we should stop trying to measure the cost of reproduction correctly. Oikos, 65: 349-352.

Baltzer, J.L., Hewlin, H.L., Reekie, E.G., Taylor, P.D., and Boates, J.S. 2002. The impact of flower harvesting on seedling recruitment in sea lavender (Limonium carolinianum). Rhodora. In press.

Calvo, R.N. 1993. Evolutionary demography of orchids: intensity and frequency of pollination and the cost of fruiting. Ecology, 74: 1033-1042.

Caswell, H. 1978. A general formula for the sensitivity of population growth rate to changes in life history parameters. Theor. Popul. Biol. 14: 215-230.

Caswell, H. 1986. Life cycle models for plants. Lect. Math. Life Sci. 18: 171-233.

Caswell, H. 1989. Matrix population models: construction, analysis and interpretation. Sinauer Associates, Inc., Sunderland, Mass.

Cunningham, S.A. 1997. The effect of light environment, leaf area, and stored carbohydrates on inflorescence production by a rain forest understory palm. Oecologia, 111: 36-44.

de Kroon, H., Plaisier, A., Groenendael, J. van, and Caswell, H. 1986. Elasticity: the relative contribution of demographic parameters to population growth rate. Ecology, 67: 1427-1431.

Eaton, P.B., Gray, A.G., Johnson, P.W., and Hundert, E. 1994. State of the environment in the Atlantic region. Environment Canada, Dartmouth, N.S.

FECA. 1999. Flower Export Council of Australia. Website. http:// www feca.org.au/index2.htm [site last updated December 13, 2001].

Fox, J.F., and Stevens, G.C. 1991. Costs of reproduction in a willow: experimental responses versus natural variation. Ecology, 72: 1013-1023.

Galen, C. 1994. Cost of reproduction in Polemonium viscosum: phenotypic and genetic approaches. Evolution, 47: 1073-1079.

Hamilton, M.B., and Rand, D.M. 1996. The inheritance of oligonucleotide probe DNA fingerprints and an estimate of the mating system of sea lavender (Limonium carolinianum). Theor. Appl. Genet. 93: 249-256.

Hatcher, A., and Patriquin, D.G., with the assistance of Fern, Y.F., Hanson, A.J., and Reade, J. 1981. Salt marshes in Nova Scotia: a status report of the salt marsh working group. Institute for Resource and Environmental Studies and Department of Biology, Dalhousie University, Halifax, N.S.

Horvitz, C.C., and Schemske, D.W. 1988. Demographic cost of reproduction in a neotropical herb, an experimental approach. Ecology, 69: 1741-1745.

Jackson, L.L., and Dewald, C.L., 1994. Predicting evolutionary consequences of greater reproductive effort in Tripsacum dactyloides, a perennial grass. Ecology, 75: 627-641.

Jennerston, O. 1991. Cost of reproduction in Viscaria vulgaris (Caryophyllaceae): a field experiment. Oikos, 61: 197-204.

Karlsson, P.S., Svensson, B.M., Carlsson, B.Å., and Nordell, K.O. 1990. Resource investment in reproduction and its consequences in three Pinguicula species. Oikos, 59: 393-398.

Lands Directorate, Environment Canada. 1986. Wetlands in Canada: a valuable resource. Fact sheet $86-4$. Supply and Services, Ottawa, Ont.

Lehtilä, K., and Syrjänen, K. 1995. Positive effects of pollination on subsequent size, reproduction, and survival of Primula veris. Ecology, 76: 1084-1098.

Maze, K.E., and Bond, W.J. 1996. Are Protea populations seed limited? Implications for wild flower harvesting in Cape Fynbos. Aust. J. Ecol. 21: 96-105. 
Mills, L.S., Doak, D.F., and Wisdom, M.J. 1999. Reliability of conservation actions based on elasticity analysis of matrix models. Conserv. Biol. 13: 815-829.

Olmsted, I., and Alvarez-Buylla, E.R. 1995. Sustainable harvesting of tropical trees: demography and matrix models of two palm species in Mexico. Ecol. Appl. 5: 484-500.

Pfister, C.A. 1992. Costs of reproduction in an intertidal kelp: patterns of allocation and life history consequences. Ecology, 73: $1586-1596$.

Prescott-Allen, R. and Prescott-Allen, C. (Editors). 1996. Assessing the sustainability of uses of wild species: case studies and initial assessment procedure. IUCN, Gland, Switzerland and Cambridge, U.K.

Primack, R.B., and Hall, P. 1990. Costs of reproduction in pink lady's slipper orchid: a four year experimental study. Am. Nat. 136: $638-656$.

Primack, R.B., Miao, S.L., and Becker, K.R. 1994. Costs of reproduction in the pink lady's slipper orchid (Cipripedium acaule): defoliation, increased fruit production and fire. Am. J. Bot. 81: 1083-1090.

Ramsey, M. 1997. No evidence for demographic costs of seed production in the pollen-limited perennial herb Blandfordia grandiflora (Liliaceae). Int. J. Plant Sci. 158: 785-793.

Reekie, E.G. 1998. An experimental field study of the cost of reproduction in Plantago major L. Ecoscience, 5: 200-206.

Reznick, D. 1985. Costs of reproduction, an evaluation of the empirical evidence. Oikos, 44: 257-267.

Roland, A.E., and Smith, E.C. 1983. The flora of Nova Scotia. The Nova Scotia Museum, Halifax, N.S.

Schmid, B. 1990. Some ecological and evolutionary consequences of modular organization and clonal growth in plants. Evol. Trends Plants, 4: 25-34.

Secretariat of the Convention on Biological Diversity. 2001. Handbook of the convention on biological diversity. Earthscan Publications, London.

Snow, A.A., and Whigham, D.F. 1989. Costs of flower and fruit production in Tipularia discloor (Orchidaceae). Ecology, 70: 1286-1293.

Syrjänen, K., and Lehtilä, K. 1993. The cost of reproduction in Primula veris: differences between two adjacent populations. Oikos, 67: 465-472.
Thoren, L.M., Karlssonand, P.S., and Tuomi, J. 1996. Somatic cost of reproduction in three carnivorous Pinguicula species. Oikos, 76: $427-434$.

Vivian-Smith, G., and Stiles, E.W. 1994. Dispersal of salt marsh seeds on the feet and feathers of waterfowl. Wetlands, 14: 316-319.

Westley, L.C. 1993. The effect of inflorescence bud removal on tuber production in Helianthus tuberosus L. (Asteraceae). Ecology, 74: 2136-2144.

Willson, M.F. 1983. Plant reproductive ecology. Wiley, New York.

Wisdom, M.J., Mills, L.S., and Doak, D.F. 2000. Life stage simulation anaylsis: estimating vital-rate effects on population growth for conservation. Ecology, 81: 628-641.

Zimmerman, M., and Aide, T.M. 1989. Patterns of fruit production in a neotropical orchid: pollinator vs. resource limitation. Am. J. Bot. 76: 67-73.

Zimmerman, M., and Pyke, G.H. 1988. Reproduction in Polemonium: assessing the factors limiting seed set. Am. Nat. 131: $723-738$.

\section{Appendix}

Sensitivity formula:

$$
\mathbf{S}_{\mathbf{i j}}=\partial \lambda \partial \mathbf{a}_{\mathbf{i j}}=\mathbf{v}_{\mathbf{i}} \mathbf{w}_{\mathbf{j}} /\langle\mathbf{w}, \mathbf{v}\rangle
$$

where $\partial \lambda \partial \mathbf{a}_{\mathbf{i j}}$ is the the change in population growth rate $(\lambda)$ with the matrix element in row $i$ and column $j, \mathbf{v}_{\mathbf{i}} \mathbf{w}_{\mathbf{j}}$ is the product of the $i$ th element of the reproductive value vector $\left(\mathbf{v}_{\mathbf{i}}\right)$ and the $j$ th element of the stable stage vector $\left(\mathbf{w}_{\mathbf{j}}\right)$, and $\langle\mathbf{w}, \mathbf{v}\rangle$ is the the scalar product of the reproductive value vector (v) and the stable stage distribution vector $(\mathbf{w})$.

Elasticity formula:

$$
\mathbf{e}_{\mathbf{i j}}=\left(\mathbf{a}_{\mathbf{i j}} / \lambda\right)\left(\partial \lambda \partial \mathbf{a}_{\mathbf{i j}}\right)
$$

where $\mathbf{e}_{\mathbf{i j}}$ is the elasticity value for the matrix element in row $i$ and column $j, \mathbf{a}_{\mathbf{i j}}$ is the matrix element in row $i$ and column $j, \lambda$ is the population growth rate (dominant eigenvalue of projection matrix), and $\partial \lambda \partial \mathbf{a}_{\mathbf{i j}}=\mathbf{S}_{\mathbf{i j}}$. 